Случай из практики

(C) Группа автора, 2016.

УДК 616.717.4-001.5-023.67-089.227.84:[616.833.36+616.833.37]:616.85

DOI 10.18019/1028-4427-2016-1-85-89

Лечение перелома плеча, осложненного нейропатией локтевого и лучевого нервов

В.Т. Тарчоков, И.А. Мещерягина, А.Н. Дьячков, С.П. Бойчук

Федеральное государственное бюджетное учреждение

«Российский научный центр

«Восстановительная травматология и ортопедия» имени академика Г. А. Илизарова» Минздрава России, г. Курган

\title{
Treatment of the humeral fracture complicated by the ulnar and radial nerve neuropathy
}

\author{
V.T. Tarchokov, I.A. Meshcheriagina, A.N. D'iachkov, S.P. Boichuk
}

FSBI RISC "RTO” of the RF Ministry of Health, Kurgan

\begin{abstract}
Приведен клинический пример лечения пациентки 29 лет с оскольчатым переломом диафиза плечевой кости, сопутствующим ятрогенным повреждением локтевого и лучевого нерва после двух оперативных вмешательств по месту жительства с использованием стержневого аппарата Илизарова. Выполнено оперативное вмешательство: демонтаж аппарата, реостеосинтез спицевым аппаратом Илизарова. Пункционная установка эпиневральных электродов. В послеоперационном периоде получала курс электростимуляции по электродам и накожным отведениям на протяжении 2 месяцев, сосудистую терапию, витамины группы В, прозерин, ЛФК, массаж. Электроды удалены на 57 сутки после установки. Срок фиксации в аппарате - 139 дней. Функция лучезапястного сустава, первого пальца и чувствительность кисти восстановлены.

Ключевые слова: плечевая кость, оскольчатый перелом, локтевой нерв, лучевой нерв, нейропатия, остеосинтез, аппарат Илизарова, эпиневральные электроды.
\end{abstract}

The authors presented a clinical case of a female patient, 29 years old, who admitted with comminuted humeral shaft fracture, concomitant iatrogenic injury of the ulnar and radial nerve after two surgeries made at the place of residence using the Ilizarov rod fixator. They performed the following surgical intervention: the fixator dismounting, re-osteosynthesis with the Ilizarov wire fixator. Epineural electrodes were fitted using punctures. Postoperatively the patient underwent a course of electrical stimulation by electrodes and skin leads for two months, vascular therapy, exercise therapy, massage, she received Group B vitamins, Prozerinum. The electrodes were removed on Day 57 after fitting. The fixation period using the fixator was 139 days. The function of the wrist, that of the first finger, and the hand sensitivity recovered.

Keywords: humerus, comminuted fracture, ulnar nerve, radial nerve, neuropathy, osteosynthesis, the Ilizarov fixator, epineural electrodes.

Во всех странах мира в связи с урбанизацией, повышением числа средств передвижения и связанным с этим увеличением дорожно-транспортных происшествий отмечается рост травматизма $[1,2]$.

По данным некоторых авторов, переломы диафиза плечевой кости от всех переломов костей скелета составляют 2,2-2,9 \% [3, 4] и 4-18\% - от общего числа переломов длинных костей [5]. Наблюдаются такие переломы преимущественно (60-70 \%) у лиц молодого возраста, ведущих активный образ жизни $[6,7,8]$. При упомянутых травмах достаточно частым осложнением является повреждение лучевого нерва той или иной степени выраженности [9]. Но, помимо посттравматических нейропатий, встречаются еще ятрогенные повреждения стволов нервов. В большинстве случаев это происходит при нарушении технологии оперативного вмешательства выбранного метода лечения. При чрескостном остеосинтезе - это, в основном, проведение спиц, стержней в опасных зонах оперируемого сегмента. Появление такого осложнения увеличивает как срок стационарного лечения больных, так и его общий период.

Приводимый клинический пример иллюстрирует случай нейропатии периферических нервов у пациентки с переломом диафиза плечевой кости, обусловленной компрессией нервных стволов фиксирующими элементами металлоконструкции.

Больная X., 29 лет, поступила в травматологическое от- деление № 1 РНЦ «ВТО» 28.05.15. Диагноз: оскольчатый перелом нижней трети диафиза плечевой кости. Состояние после остеосинтеза аппаратом Илизарова, нейропатия лучевого нерва. Травма бытовая, упала на плечо. В первые сутки обратилась за неотложной помощью по месту жительства. На 15 сутки после травмы выполнена операция: закрытый чрескостный остеосинтез стержневым аппаратом Илизарова. В первый день после операции отмечены признаки неврологических нарушений: парестезии по тыльной поверхности кисти и первого пальца. Выявлено отсутствие активного разгибания в лучезапястном суставе, отведения первого пальца кисти. Консультирована неврологом, выставлен диагноз: нейропатия лучевого нерва. Получала курс магнитотерапии № 10.

Через 12 суток с целью устранения контакта фиксаторов с нервным стволом выполнено перепроведение стержней-шурупов. В первые сутки после повторной операции отмечена парестезия, чувство жжения в области тыльно-наружной поверхности кисти, наружной поверхности четвертого и пятого пальца.

Для дальнейшего лечения самостоятельно обратилась в ФГБУ «РНЦ «ВТО» имени академика Г.А. Илизарова» (рис. 1, 2). В предоперационном периоде консультирована неврологом, нейрохирургом, диагностирована травматическая нейропатия лучевого и локтевого нервов слева. Проведено ЭНМГ исследование, подтверждающее снижение проводимости по нервным стволам локтевого и лучевого нервов.

Тарчоков В.Т., Мещерягина И.А., Дьячков А.Н., Бойчук С.П. Лечение перелома плеча, осложненного нейропатией локтевого и лучевого нервов // Гений ортопедии. 2016. № 1. С. 85-89. 

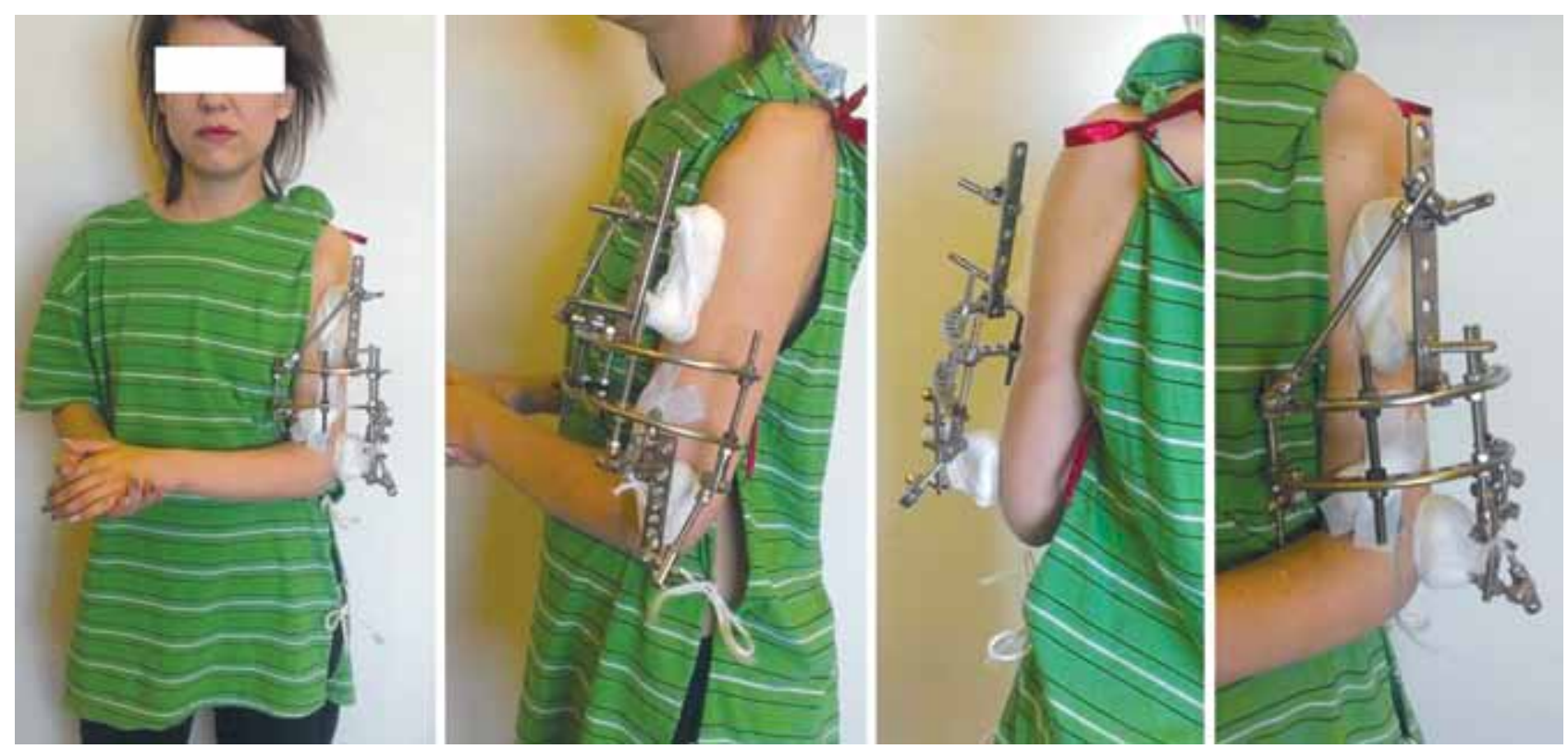

Рис. 1. Внешний вид больной Х., компоновка аппарата при поступлении в ФГБУ «РНЦ «ВТО» имени академика Г.А. Илизарова»

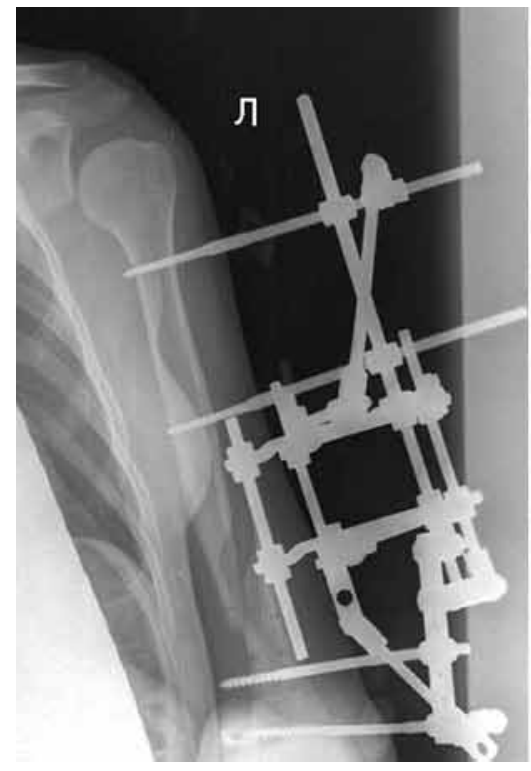

Рис. 2. Рентгенограммы левого плеча больной Х. при поступлении

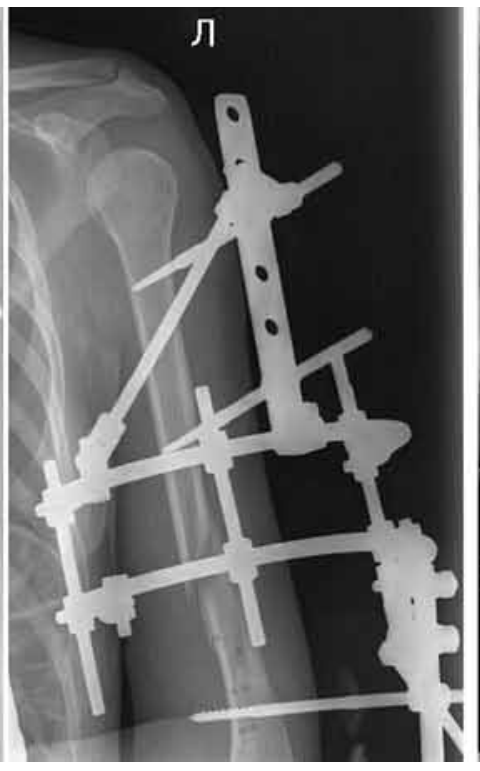

нии
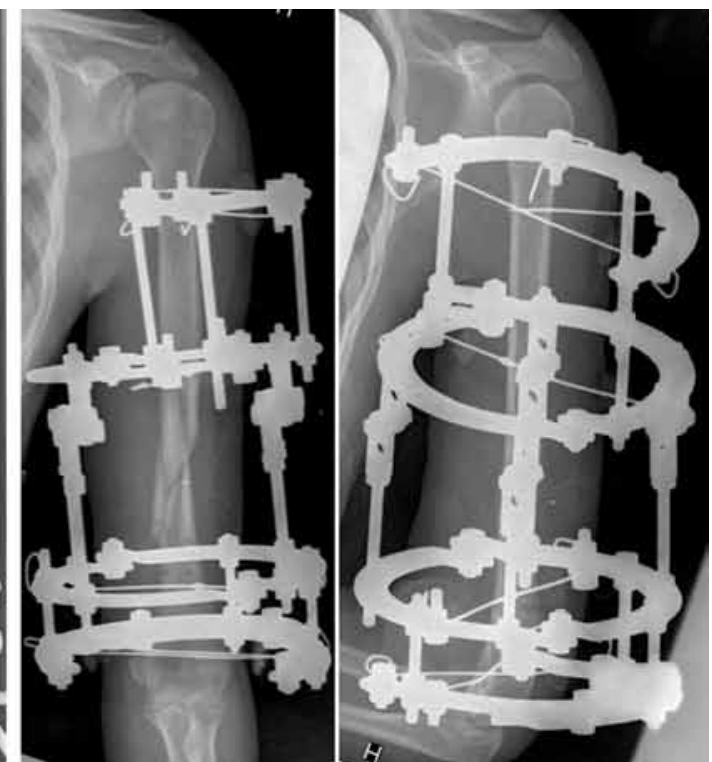

Рис. 3. Рентгенограммы левого плеча больной X. после операции
На 2 сутки после поступления в центр Илизарова (14 день после повторного оперативного вмешательства) нами выполнена операция: демонтаж аппарата, реостеосинтез спицевым аппаратом Илизарова. Пункционная установка эпиневральных электродов. Достигнуто удовлетворительное стояние и стабильная фиксация костных отломков (рис. 3).

В послеоперационном периоде пациентка получала курс электростимуляции по электродам и накожным отведениям на протяжении 2 месяцев, сосудистую терапию, витамины группы В, прозерин, ЛФК, массаж. На второй день больная уже отмечала уменьшение болевого синдрома, появление парестезии в проекции иннервации n. radialis и n. ulnaris. На контрольной ЭНМГ через 14 суток после операций отмечено увеличение показателей проводимости по вышеупомянутым нервам. Объем движений в лучезапястном суставе, отведение большого пальца увеличились, субъектив- но отмечала появление гипестезии по тылу кисти, поверхности первого, четвертого и пятого пальцев. Эпиневральные электроды удалены на 57 сутки после установки. Продолжен курс чрескожной электростимуляции, ЛФК.

При дальнейшем амбулаторном лечении для улучшения процесса сращения применяли известные способы стимуляции, такие как чередование компрессии-дистракции в зоне перелома и постепенный демонтаж аппарата. 23.09.15 г. аппарат окончательно демонтирован, срок фиксации 139 дней (рис. 5).

Через месяц после снятия аппарата движения в суставах левой верхней конечности у больной восстановились, субъективно отмечает улучшение тактильной чувствительности и увеличение объема движений до полной амплитуды в лучезапястном суставе, суставах пальцев кисти (рис. 6). 
Журнал клинической и экспериментальной ортопедии им. Г.А. Илизарова № 1, 2016 г.
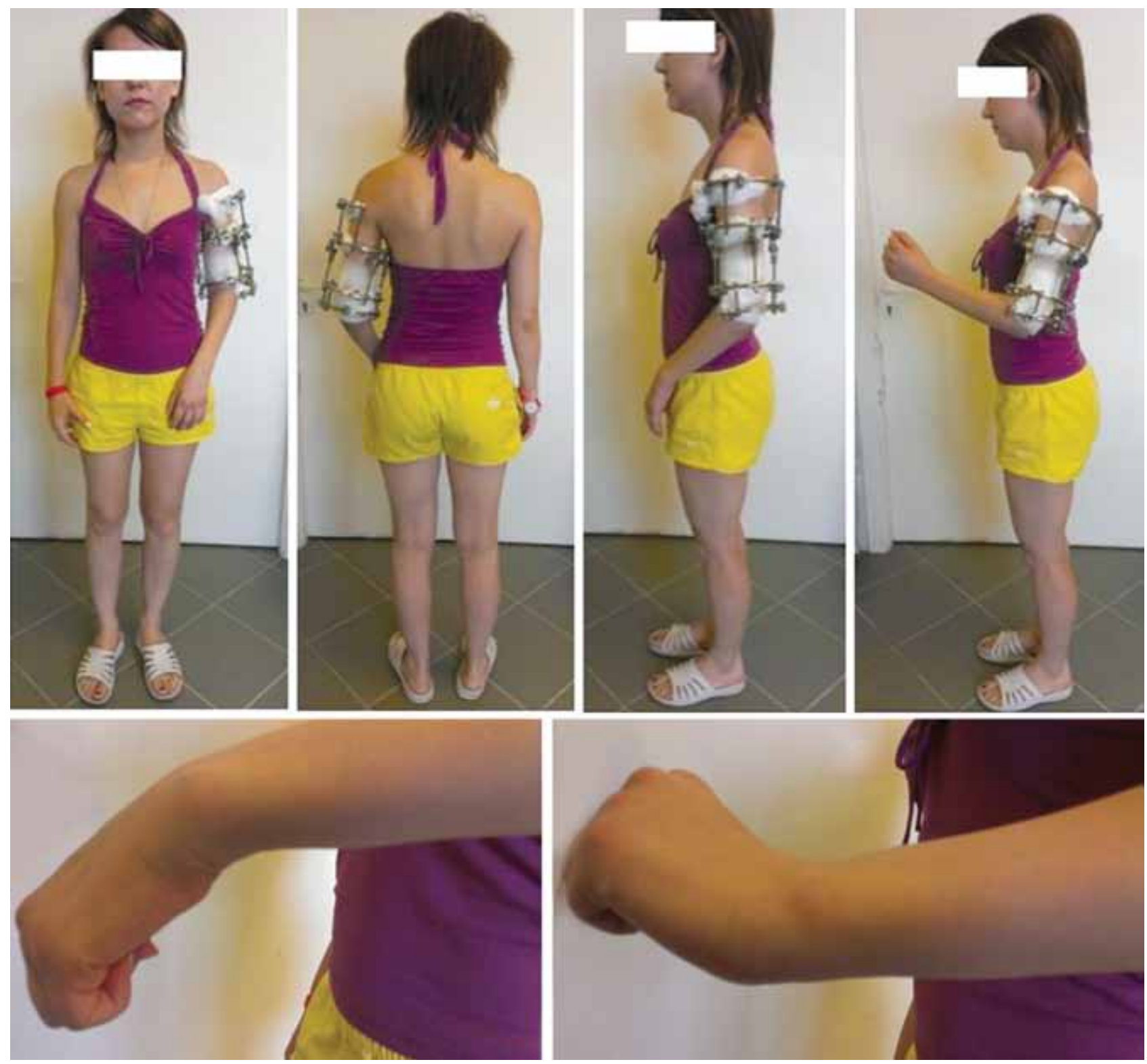

Рис. 4. Внешний вид больной Х. и объем движений в левом лучезапястном суставе на 22 сутки после операции
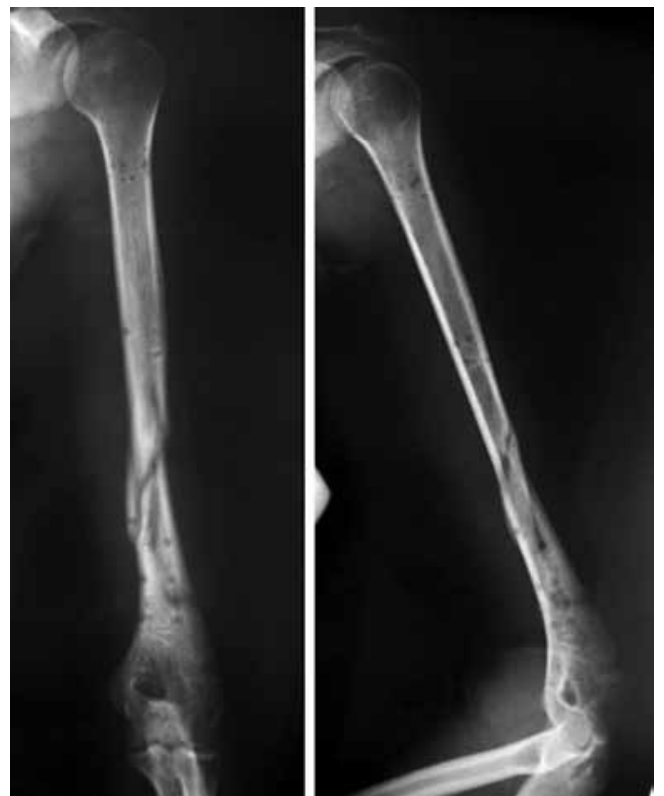

Рис. 5. Рентгенограммы левого плеча больной Х. после снятия аппарата 
Tenuí Oрпопеdии № 1, 2016 г.
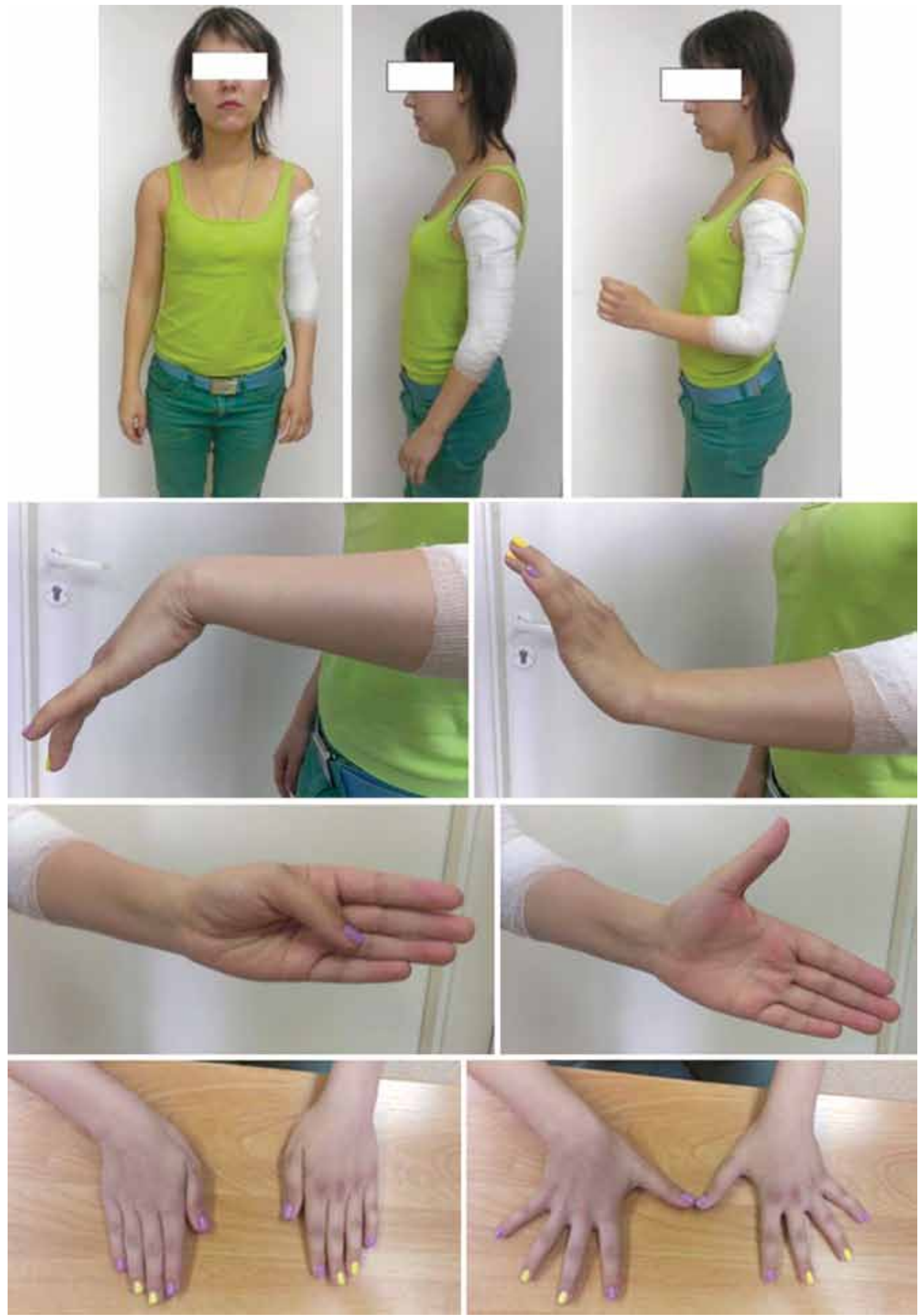

Рис.6. Внешний вид больной Х. и объем движений в суставах поврежденной конечности 


\section{ЗАКЛЮЧЕНИЕ}

При выполнении чрескостного остеосинтеза основополагающим является учет анатомо-топографических особенностей поврежденных сегментов. Нарушение данного условия приводит к возникновению ряда осложнений, требующих в последующем длительного кропотливого лечения и, зачастую, приводящих к развитию стойкой нетрудоспособности. Приведенный нами клинический пример иллюстрирует возможности успешного лечения пациентов с сопутствующей неврологической симптоматикой.

\section{ЛИТЕРАТУРА}

1. Корж А.А., Осипов Б.А., Иванов О.К. Система внеочагового остеосинтеза стержневыми аппаратами // Ортопедия, травматология и протезирование. 1988. № 7. С. 1-7.

2. Опыт лечения диафизарных переломов плечевой кости в условиях экстренной медицины / Ж.Х. Хушваков, Р.С. Юлдашев, Б.Н. Шакаров, А.Х. Каяев // Травматология и ортопедия в современном спектре: материалы VII съезда травматологов-ортопедов Узбекистана. Ташкент, 2008. С. 3435 .

3. Травматология и ортопедия : рук. для врачей : в 3 т. / под ред. Ю.Г. Шапошникова. М.: Медицина, 1997. Т.2. С. $150-155$.

4. Котельников Г.П., Мирошниченко В.Ф. Закрытые травмы конечностей. М.: ГЭОТАР-Медиа, 2009. С. 116.

5. Аскарова Д.Ш. Комбинированный метод лечения диафизарных переломов плечевой кости // Травматология и ортопедия в современном спектре: материалы VII съезда травматологов-ортопедов Узбекистана. Ташкент, 2008. С. 52-53.

6. Ключевский В.В. Хирургия повреждений: рук. для фельдшеров, хирургов и травматологов районных больниц. Изд. 2-е. Рыбинск: Рыбинский Дом Печати, 2004. 784 с.

7. Травматология и ортопедия: учебник / под ред. В.М. Шаповалова, А.И. Грицанова, А.Н. Ерохова. СПБ.: Фолиант, 2004. 544 с.

8. Extra-articular distal-third diaphyseal fractures of the humerus: A comparison of functional bracing and plate fixation / A. Jawa, P. McCarty, J. Doornberg, M. Harris, D. Ring // J. Bone Joint Surg. Am. 2006. Vol.88, No 11. P. 2343-2347.

9. Ristic S., Strauch R.J., Rosenwasser M.P. The assessment and treatment of nerve dysfunction after trauma around the elbow // Clin. Orthop. Relat. Res. 2000. No 370. P. 138-153.

\section{REFERENCES}

1. Korzh A.A., Osipov B.A., Ivanov O.K. Sistema vneochagovogo osteosinteza sterzhnevymi apparatami [The system of extrafocal osteosynthesis with rod devices] // Ortopediia, Travmatologiia i Protezirovanie. 1988. N 7. S. 1-7.

2. Opyt lecheniia diafizarnykh perelomov plechevoi kosti v usloviiakh ekstrennoi meditsiny [The experience of shaft humeral fracture treatment in the emergency medicine] / Zh.Kh. Khushvakov, R.S. Iuldashev, B.N. Shakarov, A.Kh. Kaiaev // Travmatologiia i ortopediia v sovremennom spektre: materialy VII s"ezda travmatologov-ortopedov Uzbekistana [Traumatology and orthopaedics in the current spectrum: Materials of VII Congress of traumatologistsorthopedists of Uzbekistan]. Tashkent, 2008. S. 34-35.

3. Travmatologiia i ortopediia: ruk. dlia vrachei: v 3 t. / pod red. Iu.G. Shaposhnikova [Traumatology and orthopaedics: a guide for physicians: in three volumes / ed. Iu.G. Shaposhnikov]. M.: Meditsina, 1997. T.2. S. 150-155.

4. Kotel'nikov G.P., Miroshnichenko V.F. Zakrytye travmy konechnostei [Closed limb injuries]. M.: GEOTAR-Media, 2009. S. 116.

5. Askarova D.Sh. Kombinirovannyi metod lecheniia diafizarnykh perelomov plechevoi kosti [Combined method of treating humeral shaft fractures] // Travmatologiia i ortopediia v sovremennom spektre: materialy VII s"ezda travmatologov-ortopedov Uzbekistana [Traumatology and orthopaedics in the current spectrum: Materials of VII Congress of traumatologists-orthopedists of Uzbekistan]. Tashkent, 2008. S. 52-53.

6. Kliuchevskii V.V. Khirurgiia povrezhdenii: ruk. dlia fel'dsherov, khirurgov i travmatologov raionnykh bol'nits [Surgery of injuries: a guide for doctor's assistants, surgeons and traumatologists of district hospitals]. Izd. 2-e. Rybinsk: Rybinskii Dom Pechati, 2004.784 s.

7. Travmatologiia i ortopediia: uchebnik / pod red. V.M. Shapovalova, A.I. Gritsanova, A.N. Erokhova [Traumatology and orthopaedics: a manual / eds. V.M. Shapovalov, A.I. Gritsanov, A.N. Erokhov ]. SPB.: Foliant, 2004. 544 s.

8. Extra-articular distal-third diaphyseal fractures of the humerus: A comparison of functional bracing and plate fixation / A. Jawa, P. McCarty, J. Doornberg, M. Harris, D. Ring // J. Bone Joint Surg. Am. 2006. Vol.88, No 11. P. 2343-2347.

9. Ristic S., Strauch R.J., Rosenwasser M.P. The assessment and treatment of nerve dysfunction after trauma around the elbow // Clin. Orthop. Relat. Res. 2000. No 370. P. 138-153.

Рукопись поступила 28.08.2015.

\section{Сведения об авторах:}

1. Тарчоков Вячеслав Тимофеевич - ФГБУ «РНЦ «ВТО» им. акад. Г. А. Илизарова» Минздрава России, травматолого-ортопедическое отделение № 1, клинический аспирант.

2. Мещерягина Иванна Александровна - ФГБУ «РНЦ «ВТО» им. акад. Г. А. Илизарова» Минздрава России, травматолого-ортопедическое отделение № 15, врач-нейрохирург, к. м. н.

3. Дьячков Александр Николаевич - ФГБУ «РНЦ «ВТО» им. акад. Г. А. Илизарова» Минздрава России, главный научный сотрудник научномедицинского организационно-методического отдела, д. м. н., профессор.

4. Бойчук Сергей Петрович - ФГБУ «РНЦ «ВТО» им. акад. Г. А. Илизарова» Минздрава России, заведующий травматолого-ортопедическим отделением № 1, к. м. н., врач высшей категории.

\section{Information about the authors:}

1. Tarchokov Viacheslav Timofeevich - FSBI RISC "RTO” of the RF Ministry of Health, Department of Traumatology and Orthopaedics No 1, a clinical postgraduate student.

2. Meshcheriagina Ivanna Aleksandrovna - FSBI "RISC RTO" of the RF Ministry of Health, Kurgan, Department of Traumatology and Orthopaedics No 15, a neurosurgeon, Candidate of Medical Sciences.

3. D'iachkov Aleksandr Nikolaevich - FSBI RISC “RTO” of the RF Ministry of Health, Scientific Medical Organizational-and-Methodical Department, a chief researcher, Doctor of Medical Sciences, Professor.

4. Boichuk Sergei Petrovich - FSBI RISC “RTO” of the RF Ministry of Health, Head of Department of Traumatology and Orthopaedics No 1, Candidate of Medical Sciences, Doctor of the Highest Category. 